\title{
FAVORITE GAME OU A POESIA NÃO CABE MAIS DENTRO DA VULVA DO POEMA $^{1}$
}

\section{FAVORITE GAME OR THE POETRY NO LONGER FITS INSIDE THE POEM VULVA}

\author{
Marina Baltazar Mattos ${ }^{2}$, Rogério Meira Coelho ${ }^{3}$
}

RESUMO: O presente ensaio busca pensar as novas configurações que a palavra poética tem encontrado para se espalhar, expandindo-se para além dos lugares e formas tradicionalmente resguardados para ela. Para isso, parte-se de abordagens e perspectivas teóricas, como Literatura expandida (PATO, 2012), arte e escritura expandidas (SANTOS; REZENDE, 2011) e "literatura fora de si" (GARRAMUÑO, 2014, p.43), em uma tentativa de elaborar fenômenos como a incorporação da palavra por artistas plásticos e o Slam, que vêm atravessando nosso contemporâneo. Especificamente a obra Favorite Game (1990), do artista plástico José Leonilson, e Lírica de uma favelada (2018), da slammer Nivea Sabino, servirão como mote para se analisar como a palavra desborda as fronteiras do livro e se faz presente em obras plásticas, que também podem ser lidas como inscrições poéticas, e, na rua, espaço para livre criação poética.

PALAVRAS-CHAVE: Literatura expandida; José Leonilson; Slam; Nívea Sabino.

ABSTRACT: This essay seeks to think about the new configurations that the poetic word has found to spread, expanding beyond the traditionally protected places and forms for it. For this, we start from theoretical approaches and perspectives, such as Expanded Literature (PATO, 2012), expanded art and writing (SANTOS; REZENDE, 2011) and "literature outside of itself" (GARRAMUÑO, 2014, p.43), in an attempt to elaborate phenomena such as the incorporation of the word by plastic artists and the Slam, which have been going through our contemporary. Specifically the work Favorite Game (1990), by the plastic artist Jose Leonilson, and Lyric of a slum (2018), by the slammer Nivea Sabino, will serve as a motto to analyze how the word overflows the boundaries of the book and is present in plastic works, which can also be read as poetic inscriptions, and in the street, space for free poetic creation.

KEYWORDS: Expanded literature; José Leonilson; Slam; Nívea Sabino.

\footnotetext{
${ }^{1}$ Texto inicialmente apresentado no XVI Congresso Internacional Abralic, em julho de 2019, por um dos autores, no simpósio Poesia contemporânea: crítica e performance. Sofreu alterações desde a apresentação, rica de reflexões, até o resultado final: escrita a quatro mãos e tentativa de buscar as respostas das perguntas iniciais, que geraram mais perguntas, nos trazendo até aqui.

${ }^{2}$ Mestranda pelo Programa de Pós-Graduação em Letras: Estudos Literários (pós-lit) da FALE/UFM.

${ }^{3}$ Doutorando em Estudos Literários pela UFMG.
} 


\section{Ecos da forma: formas}

Waly Salomão, em suas Algaravias: Câmara de ecos (1996), anteviu a série crescente de reflexões que o campo teórico atual vem tentando elaborar em torno de transformações e questionamentos dos sentidos e limites da literatura - afinal, "a linha de fronteira se rompeu" (SALOMÃO, 2014, p.219). Segundo essas novas abordagens e tentativas de compreensão, nomes como Literatura expandida (PATO, 2012), Expansões contemporâneas: literatura e outras formas (KIFFER; GARRAMUÑO, 2014), arte e escritura expandidas (SANTOS; REZENDE, 2011) e "literatura fora de si" (GARRAMUÑO, 2014, p.43) têm pululado, para citar apenas alguns exemplos. Todos esses conceitos apontam para um ponto em comum, que poderia ser sintetizado como uma das marcas da literatura contemporânea, que é, justa e paradoxalmente, a explosão dos limites das instâncias particulares da experiência literária, na medida em que passa a se consolidar, com bastante força, em manifestações e gestos literários que vão além dos lugares e formas de organização e intervenção geralmente associados à literatura. Outro exemplo situante dessa relação da literatura com outras áreas, ao que nos interessa aqui, é a ação performativa da poesia oral, que já tem grande suporte nos estudos da Performance, recepção e leitura, de Zumthor (2007). Para além disso, às proximidades do texto encenado, ganha força nos estudos sobre os Cenários expandidos: (Re)Presentações, teatralidaes e performatividades. (DIEGUEZ, 2010), o que nos faz pensar o texto da poesia oral(izada) com a dimensão da performance. Suportes como o livro e a voz coexistem, agora, com a instalação, os quadros e a performance: a palavra poética encontra-se espalhada por outras artes e outros discursos, e a questão da forma, por isso, assume relevância fundamental, constituindo-se como elemento-chave para entender novos problemas postos pela experiência literária em nossos dias.

Não é de hoje que a questão da forma é colocada em xeque: Theodor W. Adorno, em seu célebre ensaio "Palestra sobre lírica e sociedade" (1957), alega que uma obra diz mais de sua época do que de si mesma. Ao guardar certa sabedoria de uma sociedade, de um contexto e de uma época, cada texto vai elaborar uma articulação entre a poesia e o discurso social pelo viés de sua forma poética. Similar, e também anterior, é a obra Mimesis: a representação da realidade na literatura ocidental (1946), de Erich Auerbach, em que conceitos de representação que atravessam a literatura ao longo de sua formação são resgatados a partir da 
concepção de realidade que permeia a estilística de textos fundamentais do Ocidente. O mito de Adão e Eva, a cicatriz de Ulisses, da Odisséia, são revistos, ou melhor, relidos, por meio de sua forma, melhor fonte de seu tempo. Ainda sobre a forma, aliando poesia ao discurso social, particularmente nas performances constantemente vistas nos saraus urbanos e nas competições de poesia falada, o Slam ${ }^{4}$, podemos rever a "força-forma" (ZUMTHOR, 2007, p. 29) como difusor de linguagens artísticas que vão muito além do texto. Sendo assim, não podemos ignorar a importante lição de que a forma diz primeiro ou também sobre o texto, não sendo indissociável ao seu sentido, para chegarmos à principal questão deste ensaio: o que as formas por meio das quais se elabora e se pensa literatura, hoje, querem nos dizer?

\section{O desbunde da fronteira: campos expandidos}

É difícil falar do contemporâneo senão por meio do próprio contemporâneo. Buscar na fuga, a aproximação, na escuridão do presente, os lampejos. Então busquemos, principalmente nas intercorrências de crise na literatura brasileira, uma maneira de se pensar a reconfiguração dos modos de usar ${ }^{5}$ literatura hoje.

Celia Pedrosa, em seu ensaio "Poesia e crítica de poesia hoje: heterogeneidade, crise, expansão" (2015), nos chama a atenção para algumas tendências importantes: a noção de crise enquanto esgotamento, e sua oposição, a convivência plural em si como índice de vitalidade. No entanto, ambas nos levam a uma condição homogeneizante da pluralidade, ora negativa, ora positiva, em um binarismo reducionista que deixa de lidar com as tensões emergentes e, o mais importante aqui, que tem dificuldade de enfrentar o heterogêneo, de questionar generalizações e de discutir a partir de inflexões, operando de maneira a substituir as dicotomias que moldam a concepção de arte por contradições irresolvidas.

\footnotetext{
${ }^{4}$ O Slam é uma competição de poesia falada criada na década de 1980 por Marc K. Smith em Chicago, nos Estados Unidos. Diversas pesquisas apontam seu surgimento, bem como as especificidades do movimento que estão presentes em diversos países, como relata a atriz-MC Roberta Estrela D'alva: "Poderíamos definir o poetry slam, ou simplesmente Slam, de diversas maneiras: uma competição de poesia falada, um espaço para livre expressão poética, uma ágora onde questões da atualidade são debatidas, ou até mesmo mais uma forma de entretenimento. De fato, é difícil defini-lo de maneira tão simplificada, pois, em seus 25 anos de existência, o poetry slam se tornou, além de um acontecimento poético, um movimento social, cultural, artístico que se expande progressivamente e é celebrado em comunidades em todo o mundo." (D’ALVA, 2011, p. 120).

${ }^{5}$ Ressaltamos aqui o verbo "usar" para se tratar de literatura em uma referenciação dupla e ampla: em primeiro lugar, para diferenciação fundamental do verbo "ler", que não é mais o único que pode ser mobilizado quando se trata desse campo, é possível ver, enxergar, encontrar na rua, ouvir, cantar etc; em segundo lugar, em menção à revista Modo de usar \& co, importante expoente da literatura contemporânea que, embora tenha encerrado suas atividades, nos deixou grandes publicações.
} 
Marcos Siscar, em Poesia e crise (2010), nos apresenta a formulação da ideia de crise, não como conceito fechado, mas como uma saída para a produção poética contemporânea, percebendo, nela e por meio dela, maneiras de lidar com as ruínas da tradição. O tema da crise e do fim da poesia na e por meio da própria poesia configura, justamente, sua continuidade, suas possibilidades, reelaborações e expansões.

Florencia Garramuño colhe seus Frutos estranhos: sobre a inespecificidade na estética contemporânea (2014) a partir do trabalho de Nuno Ramos, Fruto estranho (2010), que questiona a especificidade de um meio ao utilizar vários meios ou suportes diferentes entrecruzados, e a partir da ideia proposta por Rosalind Krauss, "expanded field"7 (1979), que propõe a expansão como potencializadora maneira de lidar com as categorizações. Ao buscar uma saída da especificidade do meio, chega-se à ideia de expansão das linguagens artísticas que desborda os muros e as barreiras de contenção. A partir da fuga constante das molduras e dos lugares de pertencimento, conseguimos começar a pensar em uma forma poética que consiga abarcar as manifestações literárias que vêm acontecendo, justamente por não ter uma forma fixa, específica, por não pertencer a um campo, podendo pertencer, assim, a vários. Ao não pertencimento está ligada a noção de continuidade entre ficção e realidade, uma das dicotomias mais antigas da literatura, agora reconfigurada enquanto tensão. Só é possível compreender uma nova forma expandindo as fronteiras existentes entre os conceitos pré-estabelecidos.

\footnotetext{
${ }^{6}$ A partir deste trecho, acreditamos que fica claro que essa expansão de campos possíveis não é apenas consequência de uma crise de versos, mas também uma reconfiguração teórica, a partir de fenômenos que nos inquietam, de formas, incorporações e linguagens que não se restringem a conceitos determinados anteriormente, e que vêm ganhando, cada vez com mais força, atenção dos estudos literários.

${ }^{7}$ É importante ressaltar que Rosalind Krauss cunha este termo, "expanded field”, elaborando, particularmente, um campo expandido para a escultura, enquanto Florencia Garramuño se vale da expressão para elaborar a expansão do próprio conceito de expansão.
} 


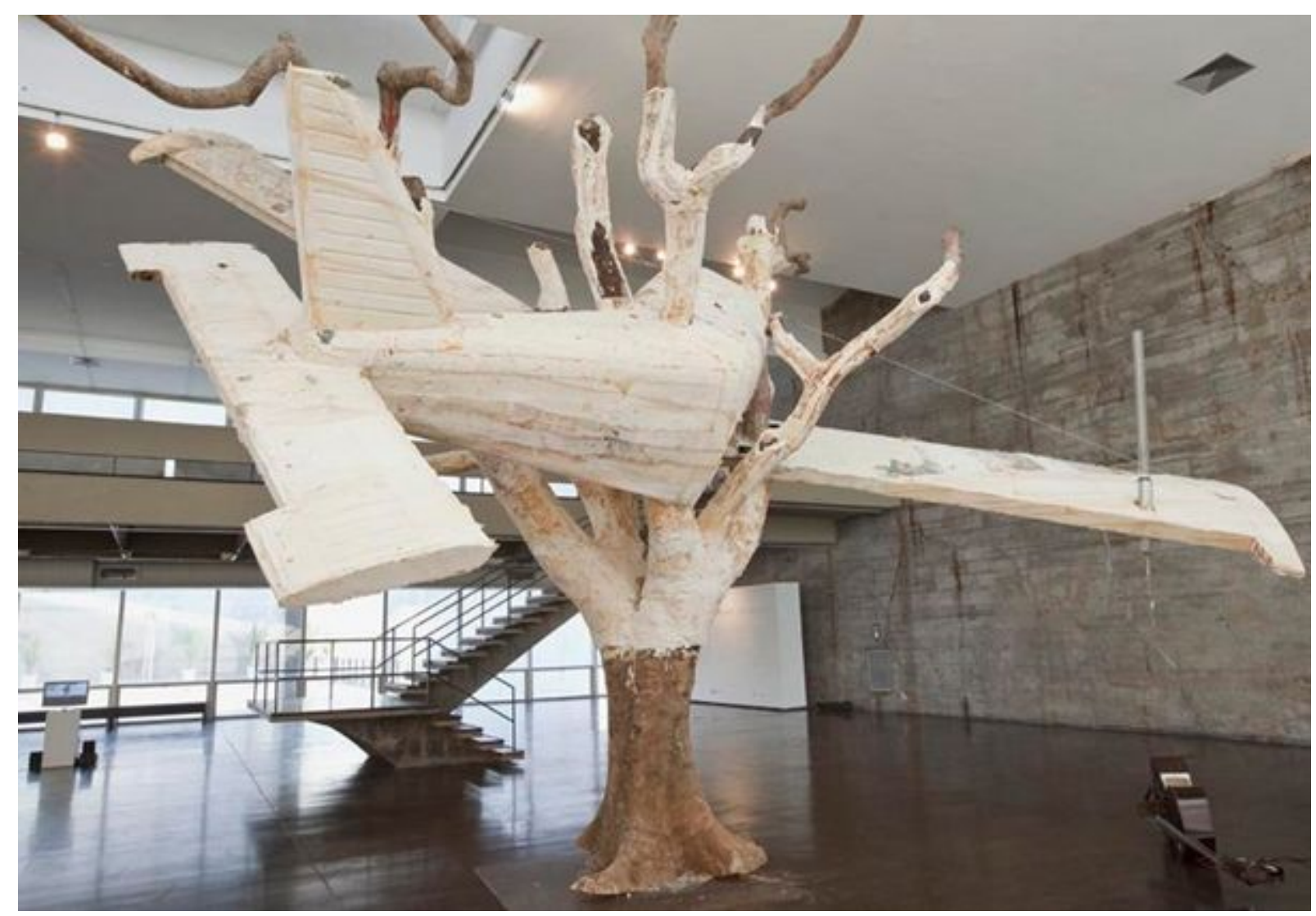

Fig. 1 - Fruto estranho (2010), Nuno Ramos

Fonte:

$<$ http://www.nunoramos.com.br/portu/comercio.asp?flg_Lingua=1\&cod_Artista=110\&cod_Serie=106 $>$.Acesso em 12 jul 2019.

O lugar da imbricação aqui é, pois, o campo expandido: a literatura que se figura como parte do mundo e imiscuída nele, a aproximação cada vez mais radical entre forma e vida, cruzamento de fronteiras entre o social e o poético - "Agora, entre meu ser e o ser alheio/ a linha de fronteira se rompeu" (SALOMÃO, 2014, p.219).

Se a fronteira demarca o limite, o extremo, o fim de algo, consequentemente marca o início, a extremidade, o limite de algures e, concomitantemente, seu "Exterior", como é o título do poema de nosso poeta desbundado Waly Salomão. O exterior, no caso, não é apenas aquilo que está de fora, denotando o que nos é desconhecido, mas também o começo daquilo que podemos perscrutar - se a fronteira se rompeu, se acabou, os campos expandidos expandiram, podemos começar.

Favorite game $e$ Lírica de uma favelada: realidade versus ficção 
Diante desse cenário, desse universo no qual, segundo palavras do filósofo francês Jean-Luc Nancy, "a própria poesia pode perfeitamente encontrar-se onde não existe propriamente poesia" (2005, p.11), a obra de José Leonilson ${ }^{8}$ pode ser lida como uma inscrição também literária: a incorporação da palavra escrita em seus desenhos, figuras, gravuras, bordados, montagens, autorretratos e instalações nos permite uma tentativa de leitura da produção artística de Leonilson como poética, e do artista, também como escritor. Ao nos depararmos com o seu trabalho, é possível perceber o acúmulo das palavras que se misturam e até mesmo se confundem com imagens e números, resultando e resultado de fronteiras mais fluidas no campo das artes, território que se expande e transborda em novas linguagens e proposições. Ao ampliar e hibridizar os domínios permeados pela poesia, em Resistência da poesia (2005), Nancy nos apresenta uma linguagem sempre por vir, em processo, em construção, na busca por um sentido que nunca está pronto - “o sentido da poesia é um sentido sempre por fazer" (Ibid, p.10) -, marcada pelo estranhamento, pela impropriedade e pela alteridade, em um movimento de não coincidência.

Uma proposição semelhante é estabelecida por Alberto Pucheu, ao tentar descrever um novo fenômeno poético e literário, apoesia contemporânea (2014) - conceito homônimo ao livro que o carrega - em que o $a$ que precede o vocábulo poesia é uma negação, um convite à alteridade, à não-poesia, à diferença, à transformação, enfim, às novas formas de arte que nos rodeiam. A partir da fronteira entre a literatura e as artes plásticas, o crítico carioca tece considerações sobre o graffiti, a pichação, as intervenções urbanas em geral, convocando o estatuto de arte para muros e circuitos fora de museus, mostrando que as manifestações poéticas têm expandido seus lugares tradicionais e vêm crescendo em superfícies, no mínimo, não esperadas ou reservadas para elas.

Pensando na obra Favorite Game (1990), de Leonilson, em que os traços de um homem são ladeados pelas palavras "truth" à direita e "fiction" à esquerda, esse movimento de não coincidência é posto à prova em forma de jogo: a alteridade do sujeito poético se constrói não só na e pela imagem, mas também pelas palavras que o rodeiam, e que formam uma das dicotomias mais antigas da literatura: realidade e ficção. O trabalho com a mímesis não só amplia o campo possível de pertencimento da gravura ao domínio das artes plásticas,

\footnotetext{
${ }^{8}$ José Leonilson (1957 -1993) - artista cearense cuja morte precoce não conseguiu findar a diversidade e a multiplicidade de significados presentes em suas criações -, inicialmente vinculado à Geração de 80, viaja o mundo em uma espécie de descobrimento do eu e do que é sua arte, radicando-se, depois, em São Paulo, onde vem a falecer, em 1993. Sua casa, no bairro Vila Mariana, hoje sedia o Projeto Leonilson, cuidado por familiares do artista, organizando seus trabalhos, exposições e catálogos. Sobre o Projeto Leonilson: <http://loja.projetoleonilson.com.br/empresa $>$. Acesso em 28 set 2019.
} 
mas convoca também um outro nível de interação, o transbordamento de limites, e o convite à literatura se dar fora de seus suportes tradicionais. Além disso, o artista brinca, desde o título, em um jogo, questionando as formas de uso, os desígnios, as dicotomias: por meio de uma composição simples, mínima, uma figura masculina nua sem rosto, com o sexo marcado discretamente a identificar o gênero, ladeado por duas palavras que são também noções que emolduram e dividem em dois a existência do sujeito - mais do que uma vítima, o personagem obtém prazer nesse jogo, em seu Favorite game.

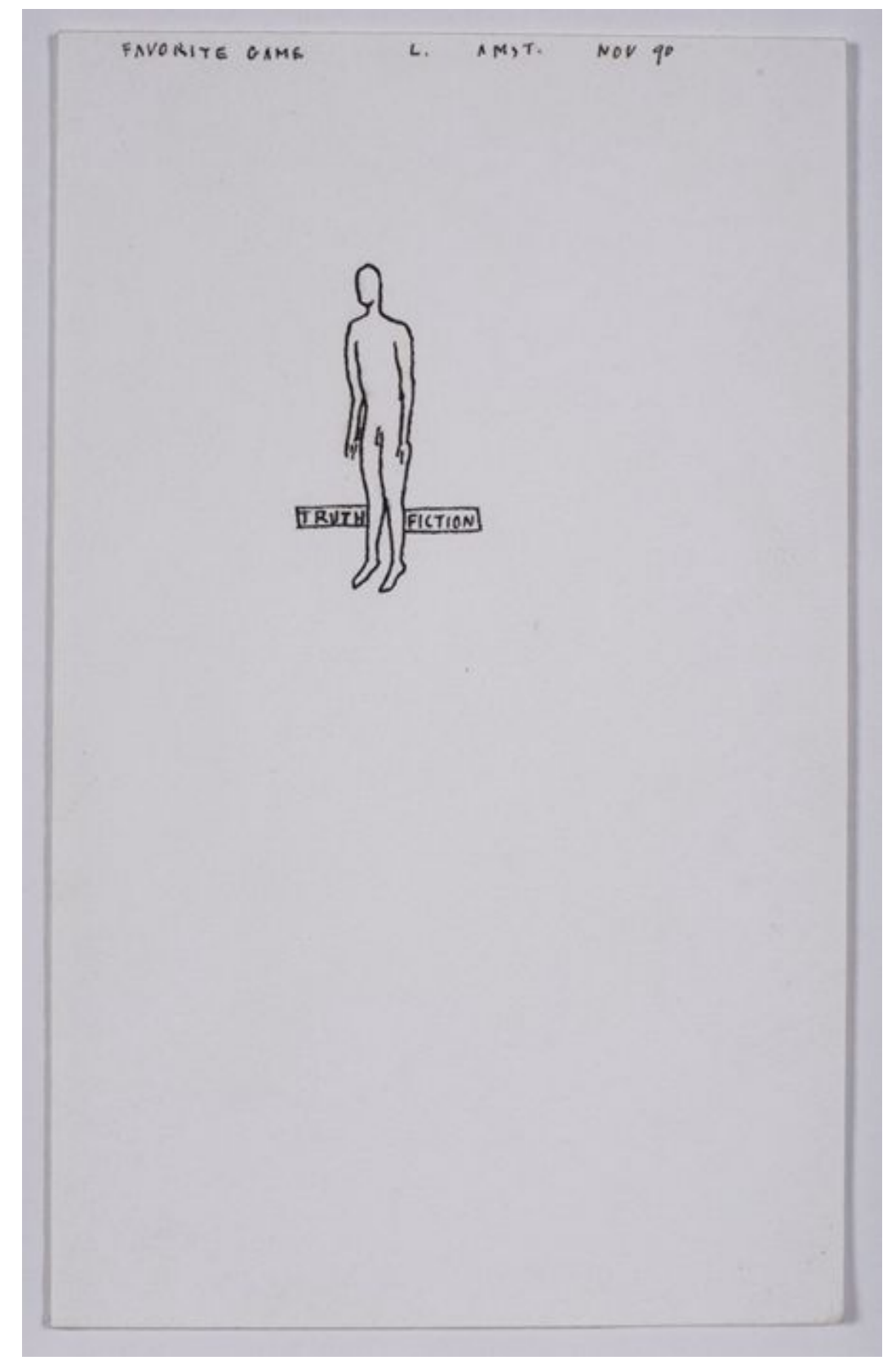

Fig 2 - Favorite Game (1990), José Leonilson Fonte: PEDROSA (2014, capa e p.33) 
Se, como propõe o filósofo francês Jean-Luc Nancy (2005), a poesia pode ser encontrada fora de seus lugares instituídos; se, conforme vai assegurar o crítico carioca Alberto Pucheu (2014), a poesia contemporânea ocupa lugares que colocam em xeque a institucionalidade do literário, nada desautoriza dizer que a incorporação criativa da palavra escrita por Leonilson possa ser lida como texto ou prática poética e criação afirmativamente literária.

O jogo entre essa prática poética e performance, a que se revela também nos Slams, hibridiza formas que se aproximam do que poderíamos chamar de uma literatura expandida, assim como de outras artes que se valem da cena. Um exemplo desse jogo, que ganha força com a "presença irredutível de um corpo" de que fala Zumthor (2007, p.38), é a poeta mineira Nívea Sabino ${ }^{9}$.

\section{LÍRICA DE UMA FAVELADA}

Eu gasto muito

É com passagem

Coração selvagem

Animália de mais valia

Que me convida

A ousar ser nós

Transformando o engasgo

Num fuzilo

Só!

Resolvi lutar

Com o que não tive acesso

Eu, réu!?

- confesso!

Me negou os versos

Me ouvindo assim

(des)faço um outro

Seu meu olhar

Quiçá

Em ti

Encanto provocar

\footnotetext{
${ }^{9}$ Nívea Sabino, poeta-slammer, ativista e educadora social, nasceu em 1980 no município que, por anos, carregou o nome do poeta Antônio Augusto de Lima, Nova Lima, onde reside atualmente. Em 2002, graduou-se em Comunicação Social pela Pontifícia Universidade Católica de Minas Gerais e, hoje, atua na coordenação política do Fórum das Juventudes, da Grande BH. É correalizadora do movimento cultural "Sarau dos Vagal" na RMBH e realiza, em parceria com o poeta Pedro Bomba, a "Roda BH de Poesia" - movimento itinerante que reúne escritores para vivenciar e recriar na capital as rodas de poesia tão tradicionais no nordeste do país. Autora de Interiorana, tendo sua primeira edição publicada pela editora Padê, em 2016, e a segunda, em 2018, através de edição independente, Nívea tem uma importante trajetória de ativismo poético no que tange o enfrentamento ao racismo, à lesbofobia, ao sexismo e outras formas de opressão, através da palavra, pelos saraus de periferias de Belo Horizonte e Região Metropolitana. Todas estas informações podem ser encontradas no Portal Geledés: $<$ https://www.geledes.org.br/ > Acesso em 27 set 2019.
} 
E desmontar

O ódio e

A aversão à cor

Que chegam primeiro

Do que quem eu sou

Li livros

Ouvi discos

Folheei jornais, me formei ao gosto

Do que tanto faz

Meu grito é o mesmo

Dos meus ancestrais

De um Amarildo

Que não volta mais

Cairão mais!

(...e

quantos mais!)

N'zinga, não deixa que

(oh!) corram

Socorro!

Nenhum

Ao meu redor Impediu o metrô

De seguir viagem

Havia um corpo

negro

estendido no trilho

e ninguém

desviou o caminho

salvem e lembrem Dandara

Esposa de Zumbi

Quem soube?

Toda periferia sangra

Que nem Manguinhos

Criança preta

Não é bandido

Cê pede paz

Mais um negro jaz!

Aqui jazz

Sambando endosso

Te funk na cara

Melodia rara

Negra graduada(mente)

Dominando a fala e a palavra

São denúncias líricas

De uma favelada

(SABINO, 2018, p. 
O poema de Nívea Sabino, por vezes recitado entre tapas na própria cara, movimentos de dedo em riste em direção ao público, afirma-se como denúncia. Para além de sua performance, traz, no texto, a justaposição das palavras Lírica e Favelada, que revela o desejo de transgressão de uma contradição estabelecida pelas classes hegemônicas a esses termos. A emancipação anunciada pela escolha estética de ser lírica e favelada, com o suporte de mais espaços de atuação como os saraus e Slams, que permitem fazer explorar sua voz, é um ato político de sua autorrepresentação. Na performance, a autorrepresentação, já marcada no texto, ganha legitimidade quando esse mesmo corpo que fala está em cena. Nívea se afirma mulher, negra, lésbica e favelada. Todas essas designações a deixam no patamar ainda mais complexo e subalterno diante de uma cultura machista, heteropatriarcal, da elite branca na qual relata ter vivido até os trinta anos de idade. Spivak nos diz que "A questão da mulher parece ser a mais problemática nesse contexto. Evidentemente, se você é pobre, negra e mulher, está envolvida de três maneiras" (SPIVAK, 2010, p. 85). Assim, autorrepresentando-se, com seu corpo presente, no momento da poesia oral dos Slams, não é difícil entender que ela faz representadas também um grande número de mulheres líricas e faveladas de seu tempo. Além disso, podemos voltar a pensar na questão da mímesis, colocada mais uma vez, a partir das potências que circundam a realidade e a ficção do Slam. Ao competir, por meio da poesia falada, em uma espaço para a livre criação poética, em que o sujeito - ou sujeita - que se expressa, descola a poesia apenas do âmbito da página, não apenas a levando para a rua, mas também colocando em xeque, ao tratar da realidade que a cerca, que a atravessa, na pele e no corpo, todos os dias, do que pode ser ficção, e do que pode ser uma forma de elaboração. 


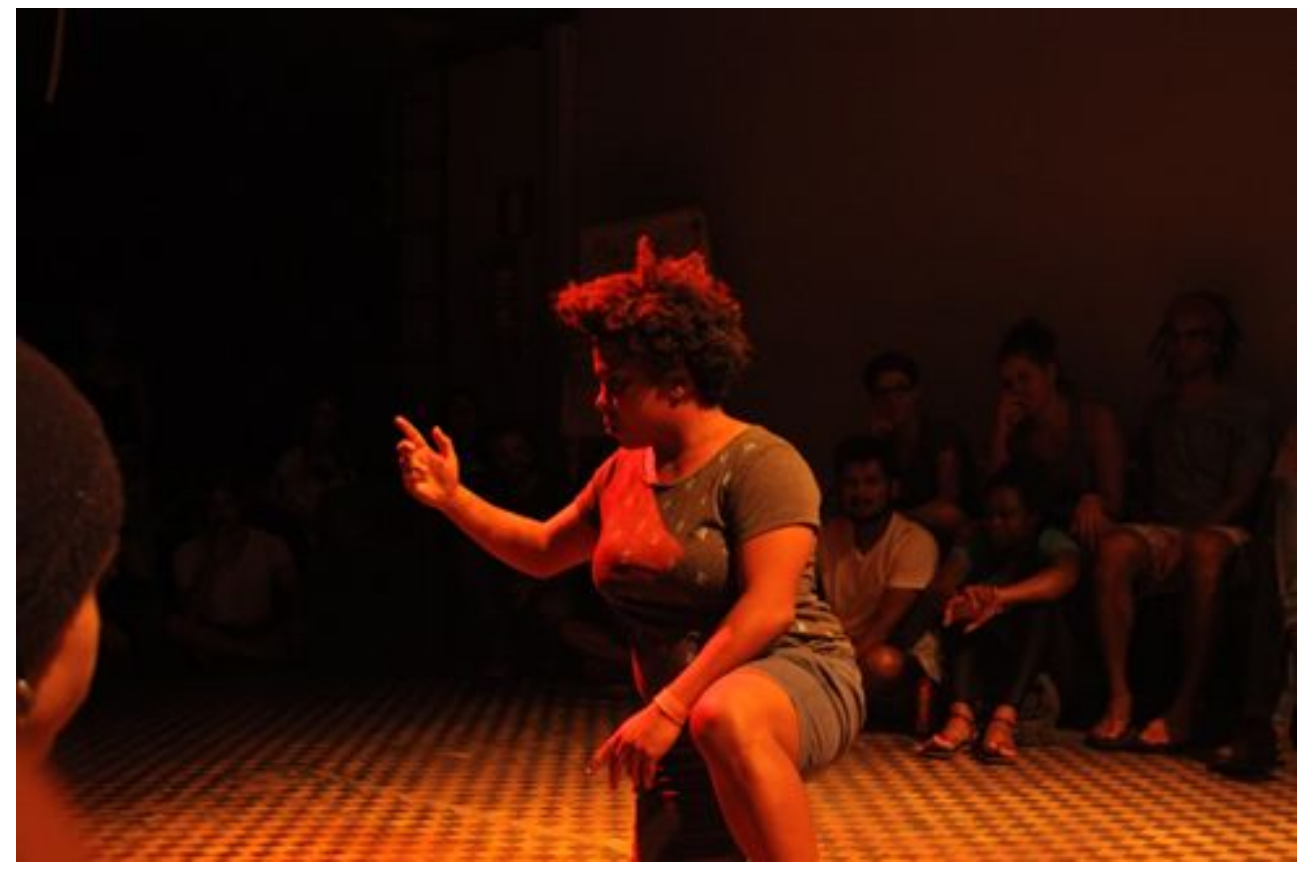

Fig. 3 - Nívea Sabino no Slam Clube da Luta em 2015

Fonte: Facebook Slam Clube da Luta, fotografia de Zí Reis.

Se uma obra, voltando a Adorno, nos diz mais de seu tempo do que de si mesma, por que não tomarmos o jogo favorito de Leonilson ou bordados ou videopoemas ou a performance de Nívea nos Slams como novas formas poéticas que vêm tomando espaço e voz diante de nós?

Encerramos, então, pelo começo, tomando nosso lugar de fronteira, em que o fim na verdade é o início (e o convite) para nossa discussão:

\section{EXTERIOR}

Por que a poesia tem que se confinar às paredes de dentro da vulva do poema? Por que proibir à poesia estourar os limites do grelo

da greta

da gruta

e se espraiar em pleno grude além da grade

do sol nascido quadrado?

Por que a poesia tem que se sustentar de pé, cartesiana milícia enfileirada, obediente filha da pauta?

Por que a poesia não pode ficar de quatro e se agachar e se esgueirar para gozar 


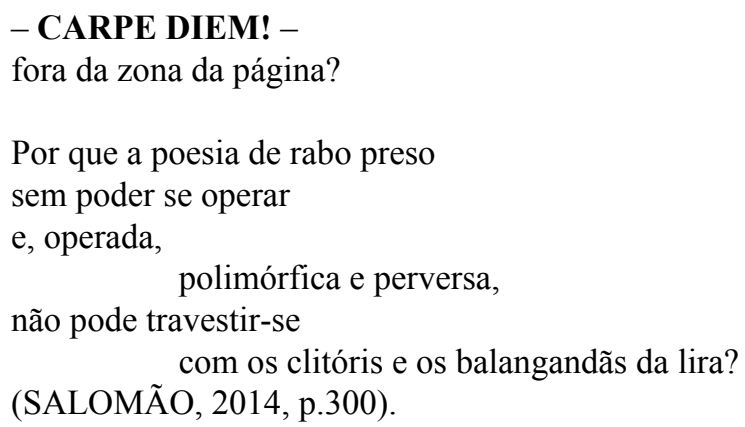

\section{REFERÊNCIAS}

ADORNO, Theodor W. Palestra sobre lírica e sociedade. In: . Notas de literatura I. Trad. Jorge M. B. de Almeida. São Paulo: Duas Cidades, Editora 34, 2012.

AUERBACH, Erich. Mimesis: a representação da realidade na literatura ocidental. São Paulo: Editora Perspectiva, 2002.

D’ALVA, Roberta Estrela. Um microfone na mão e uma ideia na cabeça - o poetry slam entra em cena. (artigo) Synergies Brésil $\mathrm{n}^{\circ} 9$ - 2011 pp. 119-126. Disponível em:

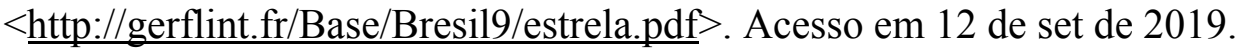

GARRAMUÑO, Florencia. Frutos estranhos: sobre a inespecificidade na estética contemporânea. Rio de Janeiro: Rocco, 2014.

KIFFER, Ana Paula Veiga; GARRAMUÑO, Florencia (Org). Expansões contemporâneas: literatura e outras formas. Belo Horizonte: Editora UFMG, 2014.

NANCY, Jean-Luc. Resistência da poesia. Trad. Bruno Duarte. Lisboa: Vendaval, 2005.

PATO, Ana. Literatura expandida. São Paulo: Edições SescSP, 2012.

PEDROSA, Adriano. Leonilson: Truth, fiction. Rio de Janeiro: Cobogó, 2014.

PEDROSA, Celia. Poesia e crítica de poesia hoje: heterogeneidade, crise, expansão. In: Estudos Avançados, 29(84), 321-333, 2015. Disponível em $<$ http://www.revistas.usp.br/eav/article/view/104967>. Acesso em 29 mar 2019.

PUCHEU, Alberto. apoesia contemporânea. Rio de Janeiro: Azougue, 2014. SABINO, Nívea. Interiorana. 2a Edição. Nova Lima/MG. (sem editora), 2018. SALOMÃO, Waly. Poesia total. São Paulo: Companhia das Letras, 2014.

SANTOS, Roberto Corrêa dos; REZENDE, Renato. No contemporâneo: arte e escritura expandidas. Rio de Janeiro: Editora Circuito, FAPERJ, 2011. 
SPIVAK, Gayatri Chakravorty. Pode o subalterno falar? Trad. Sandra Regina Goulart de Almeida; Marcos Pereira Feitosa; André Pereira Feitosa -Belo Horizonte: Editora UFMG, 2010 .

SISCAR, Marcos. Poesia e crise. Campinas: Editora Unicamp, 2010.

ZUMTHOR, Paul. Performance, recepção e leitura. Trad. Jerusa Pires Ferreira e Suely Fenerich. São Paulo: Cosac Naify, 2007.

Recebido em 30/09/2019. Aceito em 18/11/2019. 